\title{
DISCUSSION
}

\section{Instrumented laboratory flowslides}

\author{
J. D. ECKERSLEY* (1990) Géotechnique 40, No. 3, 489-502
}

\section{C. Hird and K. J. Spence, University of Sheffield}

The physical modelling of flowslides in the laboratory is beset with potential difficulties in relation to scale effects and the abstraction of reliable data. The Author is therefore to be congratulated for producing worthwhile results. However, the reproduction of full-scale failure mechanisms appears to have been more successful than the measurement of stresses at the base of the slides.

In undrained triaxial tests, following the attainment of a peak deviator stress, shear strains are responsible for the sharp increase in pore pressure accompanying the liquefaction of loose granular soil, but the stress ratio $q^{\prime} / p^{\prime}$ continues to increase until it stabilizes at the steady state. This is evident, for example, in Fig. 2. Given the similarity between steady and critical states (Hird \& Hassona, 1986, 1990), the corresponding steady state value of $\phi^{\prime}$ can be expected to be close to the critical state value and hence to the angle of repose (Bolton, 1986). If a similar behaviour pattern exists under more general stress conditions, it is hard to accept either the actual or corrected results of Fig. 14(d), which show a reduction of the stress ratio $\tau / \sigma^{\prime}$ on the horizontal plane at the base of the slide during liquefaction and imply a mobilized angle $\phi^{\prime}$ on that plane much lower than the steady state valuc. Such results could theoretically be explained by principal stress rotation, but this seems an unlikely explanation and would not be supported by other research.

A series of flow slide model tests has recently been conducted at Sheffield University. The general test arrangement is shown in Fig. 16. Fine quartz sand $\left(D_{10}=0.050 \mathrm{~mm}, D_{50}=0.075 \mathrm{~mm}\right)$ is deposited in a loose saturated state in a sloping Perspex channel and is initially restrained by a watertight barrier. The flow slide is initiated by the barrier being lifted rapidly, and it develops with multiple retrogressive slipping in a superficially similar manner to that described by the Author. Attention is, however, focused on the flow of the liquefied material along the channel bed. Data collection is achieved by both video

* The Author's name was given incorrectly as D. Eckersley when the Paper was published. and time lapse photography and by pore water pressure transducers set into the base of the channel. Although not submerged, the sand remains saturated during the test due to surface tension at the top surface.

Figure 17 shows typical results obtained at point A (see Fig. 16) for a channel bed slope of $6^{\circ}$. Initially, after the flow reaches point $A$, both the sand depth (Fig. 17(a)) and the pore pressure (Fig. 17(b)) increase rapidly. A stationary layer of sand is then deposited which grows monotonically, although unsteadily, in thickness until the flow ceases. The pore pressure, meanwhile, decreases to a steady value. In Fig. 17(b) the measured pore pressure is compared with two theoretical values: first an upper bound value $u_{1}$ calculated by assuming that in the flowing sand the effective vertical stress is zero, as it would be in a fully fluidized sand mass with a level surface, and second a lower value $u_{2}$ calculated by assuming that the effective stress on the interface between the stationary and the moving sand is just sufficient to maintain equilibrium above that level in accordance with the observation that only small accelerations of the flowing sand were observed. In each case, within the stationary sand any downslope seepage was neglected and the pore pressurc was assumed to increase hydrostatically with depth. Thus

$$
\begin{aligned}
& u_{1}=\bar{\rho} g h_{\mathrm{f}}+\rho_{\mathrm{w}} g h_{\mathrm{s}} \\
& u_{2}=\bar{\rho} g h_{\mathrm{f}}\left(\cos ^{2} \alpha-\frac{\sin \alpha \cos \alpha}{\tan \phi^{\prime}}\right)+\rho_{\mathrm{w}} g h_{\mathrm{s}}
\end{aligned}
$$

where $\bar{\rho}$ is the mean bulk density of flowing sand, $\rho_{w}$ is the density of water, $g$ is acceleration due to gravity, $h_{\mathrm{f}}$ is the depth of flowing sand, $h_{\mathrm{s}}$ is the depth of stationary sand, $\alpha$ is the bed slope angle and $\phi^{\prime}$ is taken as the angle of repose. It can be seen that the second approach provides a better fit to the experimental data.

These experiments were carried out at very small scale and need to be repeated at a larger scale so that more accurate and reliable data can be obtained. Nevertheless, they suggest that a conventional soil mechanics approach can be applied to determine the stresses at the lower boundary of a flow slide. This is in accordance 


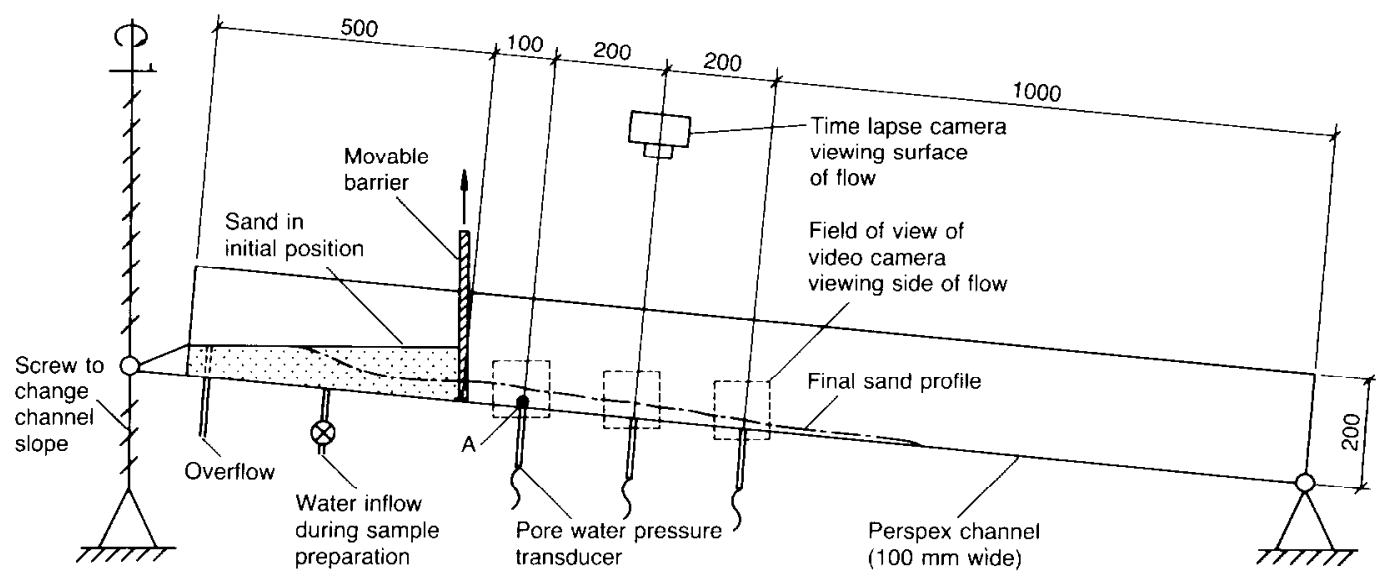

Fig. 16. General arrangement of flowslide test (all dimensions in $\mathbf{m m}$ )

with results obtained by Winterwerp, de Groot \& Mastbergen (1990) in closely related experiments on hyperconcentrated sand-water mixture flows, where steady conditions were established and the equilibrium slope angles $\alpha_{\mathrm{eq}}$ of the settled material were measured. These angles were also predicted from a consideration of the equilibrium of the flowing mixture in the direction of flow and

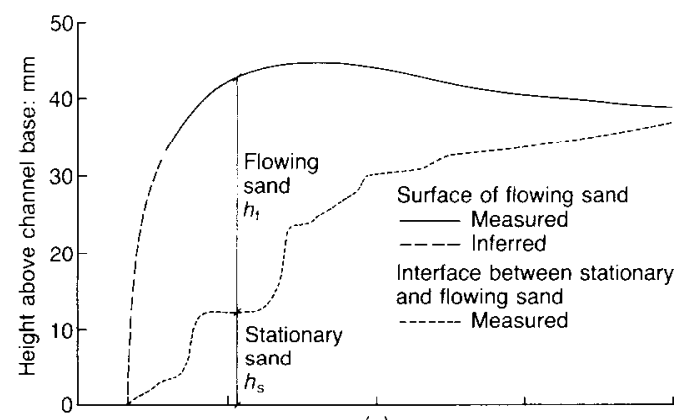

(a)

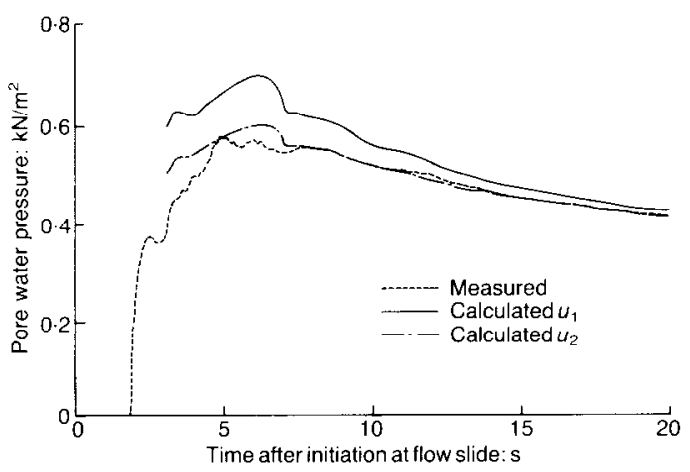

(b)

Fig. 17. Typical test results at point $A$ for a channel bed slope of $6^{\circ}$ : (a) sand depth; (b) pore water pressure it was shown that

$$
\tan \alpha_{\mathrm{eq}}=\frac{\Delta \bar{c}}{1+\Delta \bar{c}} \tan \phi^{*}
$$

where $\bar{c}$ is mean sand concentration by volume, $\Delta$ is specific density (i.e. buoyant density of solid particles/density of water) and $\phi^{*}$ is the dynamic angle of internal friction introduced by Bagnold (1954). When $\phi^{*}=\phi^{\prime}$ this equation can be rewritten in the more familiar form

$$
\tan \alpha_{\text {eq }}=\frac{\rho-\rho_{\mathrm{w}}}{\rho_{\mathrm{w}}} \tan \phi^{\prime}
$$

Reasonable predictions of $\alpha_{\mathrm{eq}}$ were obtained by setting $\phi^{\prime}$ equal to the angle of repose.

In the interior of a flow of the type being discussed a conventional soil mechanics approach to stress analysis may be expected to break down because of the effect of pore fluid viscosity (Mastbergen, Bezuijen \& Winterwerp, 1988).

\section{Author's reply}

Dr Hird and Mr Spence question the reliability of shear and normal stress measurements at the base of the experimental flowslides, and particularly the reduction of stress ratio $\tau / \sigma^{\prime}$ subsequent to the initiation of sliding as shown in Fig. 14. Their experiments on flowing sand show that stresses at the lower boundary of a flowslide are consistent with conventional soil mechanics.

It is indeed curious that $\tau / \sigma^{\prime}$ should be observed to decrease during flowsliding, contrary to expectations based on laboratory strength testing. The Author recognizes the possibility of errors in the stress measurements, and indicated in the Paper that cell performance was marred by drift and moisture ingress. However, the general 
sense of the changes in $\tau$ and $\sigma$ for cell EP0 during sliding (decrease and increase respectively) are believed to be unaffected. The final thickness of coal above the cell $(38 \mathrm{~cm})$ corresponds to a vertical total stress of approximately $3.8 \mathrm{kPa}$ (compared with $3.4 \mathrm{kPa}$ measured), giving some confirmation that the experimental values are reasonable.

The probable main source of error in Fig. 14 is the response of the adjacent piezometer $\mathrm{P} 1$ used in the calculation of $\sigma^{\prime}$ due to a clogged porous disc, as indicated in the Paper. For the measured values of shear and total normal stress of approximately $0.45 \mathrm{kPa}$ and $3.4 \mathrm{kPa}$ respectively after failure, a pore water pressure of $2 \cdot 8-2.9 \mathrm{kPa}$ (28-29 $\mathrm{cm}$ water) would be required to give $\tau / \sigma^{\prime}$ corresponding to the steady state $\phi_{\mathrm{ss}}{ }^{\prime}-40^{\circ}$. Considering the transient pore pressures developed at $\mathrm{P} 2$ and P5 and to a lesser extent P4, pressures of this magnitude at $P 1$ would not be unreasonable.

Overall, it remains clear that substantial transient excess pore water pressures were generated in the shear zone subsequent to the initiation of movement, and that static liquefaction was in this case a consequence rather than the cause of failure.

\section{REFERENCES}

Bagnold, R. A. (1954). Experiments on a gravity-free dispersion of large solid spheres in a Newtonian fluid under shear. Proc. R. Soc. A225, $49-63$.

Bolton, M. D. (1986). The strength and dilatancy of sands. Géotechnique 36, No. 1, 65-78.

Hird, C. C. and Hassona, F. (1986). Discussion. Géotechnique 36, No. 1, 124-127.

Hird, C. C. and Hassona, F. A. K. (1990). Some factors influencing the liquefaction and flow of saturated sands in laboratory tests. Engng Geol. 28, 149-170.

Mastbergen, D. R., Bezuijen, A. and Winterwerp, J. C. (1988). On the construction of sand fill dams - Part 1: hydraulic aspects. International Symposium on Modelling of Soil-Water-Structure Interactions. Delft: IAHR, ISSMFE and IUTAM.

Winterwerp, J. C., de Groot, M. B. and Mastbergen, D. R. (1990). Hyperconcentrated sand-water mixture flows over flat bed. J. Hydraul. Engng Am. Soc. Civ. Engrs 116, No. 1, 36-54. 